\title{
Exchange rate volatility A retrospective view of OCA and Central Eastern European Countries
}

\author{
Lisnaja Kelmendi Prof.Dr. Areti Stringa \\ University Of Tirana, Albania Raiffesien Bank, Albania
}

\begin{abstract}
The importance of the optimum currency area theory is increased after creation of European Monetary Union. Before euro currency, the usage of American Dollar regardless OCA theory establishment was not analyzed in the same perspective of an economic policy to control exchange rate regimes. Reviews of researches based on the empirical analyses to provide an examination of the data between countries of Eurozone and Europe, are necessary to rethink the effects of joining a monetary union. Countries which want to enter EMU must fulfill OCA criteria's. A crucial factor is the exchange rate volatility. The paper is a retrospective of Hovarth study and the model enriched by him to analyze the criterias met by CEEC. Before taking a decision we must first interpret accurately the results achieved, and then create possibilities to widen European Monetary union with those countries which are ready to adopt euro, and will experience deeper integration and cycle synchronization ex post. This is an important now day issue, especially following the dynamic changes in European Union.
\end{abstract}

Keywords: model, approach, analysis, shock, exchange rate, volatility, pressure, trade integration, business cycle

\section{Introduction}

Optimum currency areas have been seen as possibilities to decrease transaction costs of flexible regimes and unfamiliar currencies. Now days the technology helps in elaborating the information. Cost gets smaller as the time passes. Flexible exchange regimes are considered risky, volatile and unsecured. Are all these speculations and accuses a way to create monetary unions all around the world? Is the perfect solution the fixed exchange rate? The free money movement exists only in theory and it is very academic. Free movement will provoke high volatility, which impacts the output and the financial health system, and for this reason the policymakers want to soften the costs.

European Union is a touchable reality and it is a good example to be analyzed practically. Optimal currency area theory rose from the discussions concerning exchange rate regimes and regulations under disequilibrium of payments balance. Mundell (1961) challenged Friedman view emphasizing the difference between optimal area and actual area. He established other macroeconomic parameters interventions as capital movement, labor mobility, fiscal transfers ecct, to bring countries in equilibrium without a necessary flexible regime. Other authors after as Kawai (1987), McKinnon (1963) and Kenen (1969) included openness and output diversification as financial tool adjustments.

The later articles of Mundell (1973a, 1973b) argument the OCA theory differently. If countries adapt a common currency without substantial effect in purchase parity, they will benefit from the better capital allocation, being relief from the insecurity of exchange rate. The foreign reserve will be increased less proportionally with the economy. The asymmetric shocks of these countries will not affect the output to decrease, because the shock's absorption cost is going to be spread effectively during the time.

One of the most critical questions is how important the trade integration is. There are two points of view on this issue. First, countries can benefit from a deeper trade integration leading to a more effective resource allocation. The business cycle synchronization will be higher between countries based on economy of scales. This will prevent a high probability of a shock asymmetry occurrence. Second, believers of the other view argument that deeper trade integration will lead to a higher specialization. This will bring a concentrated industrial activity. Most probably shocks will occur in the future (the output is less diversified and will add other costs to European Union).

Frankel and Rose (1998) shows that the closer the integration is, the higher the correlation of business cycles is going to be. They emphasize that business cycles and trade integration are linked endogen processes in creating European Union. Thus, they prove that countries can accomplish OCA criteria ex post; even they did not fulfill them ex ante. Joining European Union increases trade linkage within countries making business cycles more symmetric among union members. The argument given by Frankel and Rose (1998) arrives in a conclusion that implementation costs of common currency are relatively low. Anyway there are doubts for the credibility of OCA criteria endogenity. In a theory model Hallet and Piscitelli (2001) show the validity of endogenity hypothesis, which is unsecured and linked in a big mass with the structural convergence in the initial 
phase of monetary union. Without a sufficient structural convergence, the common currency implementation would cause large divergence. Maybe a more interesting issue is not searching an optimal regime of the exchange rate, but instead searching an optimal volatility of the exchange rate. Bayoumi and Eichegreen (1998) suggest an approach to model the volatility of exchange rate, which considers the multi dependency of economies. The model presented in this paper is not the original of the Bayoumi and Eichegreen (1998) idea, it is the model developed from Horvath (2005).

\section{OCA Theorical Views}

OCA is taking a great importance after creation of EMU. A part theory, the focus today is empirical analysis of the data in Eurozone. Countries in EMU have endured changes and other countries not part of the common currency are ready to join the area. To provide a good analysis the OCA criteria's must meet, especially openness and trade relations. Before presentation of euro currency, there have existed negotiations to enlarge Eurozone with CEEC countries. It is to be valued if the candidate countries are more or less adaptable to enter in EMU. Countries joining monetary areas experience huge changes of business cycles then before entering. One factor is monetary policy and the other is the closer trade relations among countries increasing correlation in cycles. One of the most important researches in empirical field is Frankel and Rose (1998). The authors argue of some OCA endogen criteria are converging after joining European Union, as for example international trade and business cycles.

Frankel and Rose (1998, f.1024) declare that: “....some countries may seem poor candidates for European Union, based on historical data. But the entrance on the EMU for any reason can cause a substantial impulse to widen trade resulting in more correlated cycles". This means that a country has more possibility to meet criteria ex post than ex ante. This hypothesis is the so called "endogenity hypothesis" According to Krugman (1993) the members of a monetary area become less diversified and more touchable by supply shocks. Their incomes become less correlated resulting in more individual business cycles. If the membership in a monetary union is not seen ex ante, it will not be seen ex post. This is the well know "Krugman specialization hypothesis".

An important work regarding empirical analysis of OCA is the paper of Bayoumi and Eichengreen (1998). They link the OCA conditions with the mobility and pressure of the exchange rate and suggest that criteria meeting in a larger scale create bilateral stable exchange rates and low pressures. This paper was enriched much from Horvath (2005). He applied the empirical analysis for the CEEC countries analyzing their conditions by including more variables. Horvath (2007) says that:" ...if country criteria include substantial fluctuations in exchange rate, then the adoption of the currency cannot be a good choice"

Horvath (2005) analyzes the determinant of bilateral rate volatility and the pressures on the rate for 20 countries using the basic criteria of OCA. In this case is controlled the hypothesis that if countries that meet criteria's in a lower scale, afford higher pressures and volatilities. Countries facing a similar shock must have a stable exchange rate. The author discovers that the suggested variables from OCA theory explain the dynamic of exchange rate. He evidences more open and less financially developed economies, which are afraid to let exchange rate moving freely. We must emphasize something. The free movement of exchange rate must have high application.

Milton Friedman ${ }^{1}$ used an analogy which is very exact and illuminative:" Each summer it is easier to move solar time then to coordinate a huge number of people and change all the activities by one hour". Horvath (2005) use a different approach concentrating on the second moment of the exchange rate, which means trying to define the determinant of exchange rate volatility, based on quarterly data for 20 countries during 1989-1998. Hovarth uses "out-of-sample approach" to forecast the exchange rate volatility and the pressures toward it for many countries of Center and East Europe, identifying the part of rate volatility linked explicitly with the OCA criteria. Horvath, on his research (2005, p. 3) says: "If volatility and pressure will remain high and will continue in the future (whatever the difficulty to find the reference point), this will testify that the adoption of euro maybe not beneficent for these countries."

In theory the utility of a country owning its currency lessen when countries are subject to common shocks. Subsequently the OCA theory emphasizes the case of individual shocks occurrence after monetary union creation, where the union is possible to be stable if the economy reacts against shocks with a smaller loss in welfare. From the other side, Mundell (1973) emphasize that countries which are subject to individual shocks can create a monetary union if they are able to diversify enough the risk. The basic assumption that Horvath use $(2005$, p.4) is "...the substantial instability of exchange rate or the high pressures show that nominal exchange rate continue to remain an important regulatory mechanism. After, the trade integration and the business cycles synchronization stay as representatives for spreading shock in national level. Suchlike we expect the deeper integration and the higher cycles synchronization, will be associated with a greater stability of exchange rate".

${ }^{1}$ Expressed in the FRIEDMAN, M. (1953) paper 
The size of a country is important. Small countries usually tent to be more open and predisposed to take on a common currency. This fact is mentioned also by Horvath (2005), who says that a country utility holding its currency is decreased if the economy mass of the country is small.

\section{Empirical Analysis (Model)}

Horvath (2005) has used as sample of 20 developed industrial countries for the period 1989-1998. He has analyzed the variables that influence the bilateral exchange rate volatility.

The estimating equation is:

$V O L_{i j}=\alpha+\beta X_{i j}+\chi F I N_{i j}+\delta E U R O P E_{i j}+\Phi D O L V A R_{i j}+\varphi E U$ core $_{i j}+\gamma I N F L_{i j}+e_{i j(1)}$

The depended variable is the exchange rate volatility. $X_{i j}$ is a vector with the variables of OCA, which are the asymmetry of business cycles, trade relations, the change of the structure of the exported goods, openness and the economic size, all these between country $\mathrm{i}$ and country $\mathrm{j} . \mathrm{FIN}_{\mathrm{ij}}$ captures the financial development level and EUROPE $\mathrm{E}_{\mathrm{ij}}$ is a dummy variable taking the value 1 if both countries $\mathrm{i}$ and $\mathrm{j}$ are European. DOLVARij takes the American Dollar movement. EUcoreij estimates the greater real convergence hypothesis among these countries: Germany, Belgic, Austria, Netherland and Swiss. INFLij represents the differential of inflation rate.

The volatility of bilateral exchange rate is measured as the standard deviation of the change from quarter $\mathrm{t}$ to quarter $\mathrm{t}+1$, of the nominal exchange rate logarithms between countries $\mathrm{i}$ and $\mathrm{j}$. Author uses the generalized method of moments because some of variables are endogen. Results show that the deeper trade relations reduce strongly the bilateral exchange rate volatility, while the change in the structure of exported goods is expected to increase it. This change reflects the shocks by industries. Shocks are more similar if countries display a competitive advantage in the same export industries.

The larger openness is associated with lower volatility of the exchange rate, same as the financial deepening. The linkage between openness and exchange rate volatility suggest that many economies fear volatility. Intelligibility the fluctuations on American Dollar affect the fluctuations of other currencies. The exchange rate volatility is visibly smaller in European countries, reflecting the existence of ERM. There is no difference in the main countries of Europe with the peripheral countries. The same analysis the author performed for the pressures on the exchange rates. The change in export is not affected from the pressures, showing no reaction of policymakers toward special industrial shocks.

The openness is negatively related to the pressure. The financial development is related positively with exchange rate pressures. The financial developed countries are able to tolerate bigger pressures of exchange rate. Counterpart the dummy variable Europe is very important but with a negative sign, suggesting that small pressure predominate among these countries on bilateral basis. The dummy variable EU core is not strongly related with the pressures.

\section{The Implication Of CEEC And Results}

Basing on OCA Horvath (2005) forecasts exchange rate volatility and the pressures toward it for the European Central East countries. He tries to estimate the scale of consistency of these countries with the Eurozone. He forecasts the volatility and the pressures by using the "out of sample" approach related with the equilibrium exchange rate. In the first step is estimated the size between volatility and criteria for developed countries. In the second step is calculated the volatility and the pressures for the CEEC countries base on the structural relationship estimated in the first step. As result we provide a forecast of exchange rate volatility and pressures for the respective countries, adjusted for the exchange rate fluctuation according to OCA. This result is interpreted as a measure of availability to adopt euro. Countries meeting OCA criteria's must have a stable exchange rate. From the other side, if the OCA criteria include substantial variation in on exchange rates or pressures if this rate is fixed, then the adoption of a common currency cannot be a good choice.

The author approach is a so called conservative evaluation because of two reasons. First, OCA criteria's can be endogen. Frankel and (1998) argue that e common currency increases the trade integration and as consequence business cycle integration. In other words, shock models after entering change with the shock models before entering, as a result of the common currency adoption. On the other side the OCA endogenity effect can be very small for the much opened countries of Central Eastern Europe, which their trade is now very oriented with the Eurozone. Second, exchange rate can generate itself rather than absorb shocks. The used sample Horvath (2005) are: Bulgaria, Czech Republic, Estonia, Latvia, Hungary, Lithuania, Poland, Slovakia, Slovenia and Romania. Data taken from Horvath (2005 and Horvath (2007) are from first quarter of 1999 up to last quarter of year 2004. 
Table 1

\begin{tabular}{lcccc}
\hline & Trade links & $\begin{array}{c}\text { Dissimilarity } \\
\text { of exports }\end{array}$ & Openness & $\begin{array}{c}\text { Financial } \\
\text { Development }\end{array}$ \\
\hline \hline Bulgaria & 0.105 & 0.287 & 114.1 & 1.53 \\
Czech Republic & 0.223 & 0.053 & 129.9 & 2.69 \\
Estonia & 0.237 & 0.106 & 163.1 & 1.42 \\
Hungary & 0.224 & 0.084 & 137.2 & 1.75 \\
Latvia & 0.099 & 0.617 & 94.4 & 1.19 \\
Lithuania & 0.121 & 0.317 & 103.4 & 1.00 \\
Poland & 0.087 & 0.093 & 64.9 & 1.62 \\
Romania & 0.112 & 0.147 & 76.0 & 0.87 \\
Slovakia & 0.256 & 0.085 & 147.7 & 2.44 \\
Slovenia & 0.160 & 0.023 & 114.1 & 1.96 \\
Eurozone & 0.177 & 0.314 & 70.3 & 2.71 \\
Eurozone - GDP weighted & 0.246 & 0.259 & 67.8 & 3.72 \\
\hline
\end{tabular}

Source: Horvath (2005)

The table 1 present OCA conditions for CEEC from 1999 to 2004 (on quarterly basis) It is obvious that trade integration with the euro area is driven from Czech Republic, Estonia, Hungary and Slovakia. The last are Bulgaria, Lithuania, Latvia and Poland. However, trade integration is generally very high achieving typical levels for Eurozone. Regarding the structural change of goods export, it has the main variations in the Eurozone comparing to CEEC. These countries of Central and Eastern Europe show comparative advantage in typical sectors for Eurozone. After all, these countries despite maybe Poland and Romania are very open. Anyway the financial development degree is generally weak versus Eurozone (before its creation) It is important to remark that the results presented in table 1 , are based on the average bilateral relations among the countries. If we use the weights (GDP of 1998 in our case), Eurozone results of the OCA conditions are more favorable. The bilateral relations within the euro area increase considerably. The bilateral goods export structure is less diversified comparing the case of not using the GDP weights. The results for openness are the same; meantime the financial intermediary is strong.

Another issue is that OCA criteria's are favorable for the mostly of the CEEC, remaining stable in long-term and do not change immediately, even the shock's models can change after entering EMU. The other step is comparing the actual and forecasted volatility and of exchange rate among countries of Eurozone and CEEC. The results clearly suggest that forecasted exchange rate is nearly Eurozone levels, meanwhile the actual volatility of exchange rate for CEEC is larger than euro area before it was created. The clear discrepancy in volatility scale term of exchange rate between Eurozone and CEEC arises from the fact that whiles a rank of these countries hold flexible exchange rate regimes, all the countries of Eurozone took part in ERM during the analyzed period and in this manner limited their exchange rate volatilities. This discrepancy is hided in the cases of the pressures toward exchange rate. It is valuable to say that Latvia and Lithuania show a relatively high volatility, regardless these countries took actions to limit exchange rate. This happens because no country anchored its currency with euro during any time of the analyzed period.

Below are presented the forecasted and actual volatility results of the exchange rate for these countries.

Table 2

\begin{tabular}{lcc}
\hline & \multicolumn{2}{c}{ Exchange Rate Variability } \\
& Actual & Predicted \\
\hline Bulgaria & 0.014 & 0.015 \\
Czech Republic & 0.026 & 0.001 \\
Estonia & 0.005 & -0.002 \\
Hungary & 0.037 & 0.001 \\
Latvia & 0.036 & 0.030 \\
Lithuania & 0.036 & 0.017 \\
Poland & 0.063 & 0.016 \\
Romania & 0.051 & 0.015 \\
Slovakia & 0.030 & -0.001 \\
Slovenia & 0.010 & 0.004 \\
\hline
\end{tabular}

Source: Horvath (2005) 
Countries holding limit on currency like Estonia or Bulgaria, experience lower volatility of exchange rate. The polish Zloty and the Romanian Leu are especially unstable in the analyzed period. There is also heterogeneity among CEEC. We see that the forecasted volatility is presided from Estonia. Lithuania and Latvia rank last (high volatility). The results related to the exchange rate pressures suggest that these countries experience pressures typical to the Eurozone. Estonia, Czech Republic, Slovakia and Hungary have the lowest forecasted pressures from the above countries. Anyway it is of interest to emphasize the actual pressures for Slovakia and Hungar, which are very high versus them included in the model.

Unfortunately, the analysis does not permit to explain of the reasons staying beyond this difference. It can be caused by many factors like economic policies credibility, labor market rigidness or the speculative attacks. Alternatively, the difference between actual and forecasted pressures can be interpreted as an excessive not fondemantal volatility. This volatility is hided after entering monetary union. In such case, countries which difference of actual and forecasted pressures is large must benefit from the euro adaption in comparison to other countries. The table of the actual and forecasted pressure is presented as below:

Table 3

\begin{tabular}{lcc}
\hline & \multicolumn{2}{c}{ Exchange Rate Pressures } \\
Actual & Predicted \\
\hline Bulgaria & 4.70 & 4.27 \\
Czech Republic & 2.37 & 2.84 \\
Estonia & 1.84 & 1.68 \\
Hungary & 4.82 & 2.60 \\
Latvia & 3.93 & 4.86 \\
Lithuania & 4.81 & 4.46 \\
Poland & 6.57 & 6.10 \\
Romania & 11.83 & 5.42 \\
Slovakia & 8.83 & 2.00 \\
Slovenia & 4.94 & 3.86 \\
\hline
\end{tabular}

Source: Horvath (2005)

According to Horvath (2005, p.15): “...the results suggest that many of the CEEC fulfill the required criteria for entering EMU, in other words they coincide well with the Eurozone."

\section{Conclusions}

The common European currency is now a reality. This fact permits us to make analysis on the real advantages and disadvantages of a monetary union creation. There have been performed hundreds of studies and research on this filed with data provided from Eurozone. Above we treated the case of Central Eastern Europe Countries and their possibility to join euro. This analysis was based on exchange rate volatility and the impact OCA criteria's have on it. We touched also the determinants of bilateral exchange rate volatility and the pressures toward it. We found that the suggested variables from the optimum currency area theory explain the dynamic of exchange rates and the pressures on the rates in a large mass. There is evidence of the fear more open economies have from the exchange rate volatility. The results do not support any important difference between the core of European Union and its peripheral part. European economies are faced in e bilateral way with a low volatility and low pressures compared to other developed countries. We than forecasted the volatility of the exchange rate together with the pressure role for the CEEC. The results suggest heterogeneity among these countries in terms of volatility and pressures. Visibly Estonia experiences low volatility and pressures. Integrality the model insinuates that the actual levels of exchange rate volatility and pressures are the same as euro countries before adopting the common currency. Therefore, it seems that Central Eastern European countries fit well with the Eurozone countries, especially in terms of trade integration, openness and similar export structure. The common currency leads to increse the trade exchange among countries of Eurozone. The model can be applied specifically for other countries of Europe which aspire to be part of European Union.

\section{References}

[1]. HORVÁTH, R. (2005): "Exchange rate variability, pressures and optimum currency area criteria: Implications for the Central and Eastern European Countries", CNB WP No. 8/2005

[2]. HORVÁTH, R. (2005): "Exchange rate variability, pressures and optimum currency area criteria: some empirical evidence from the 1990s", Applied Economics Letters, 14, pp. 1083-1086

[3]. FRIEDMAN, M. (1953): The Case for Flexible Exchange Rates, In: Essays in Positive Economics, The University of Chicago Press. 
[4]. BAYOUMI, T., AND EICHENGREEN, B. (1998): "Exchange Rate Volatility and Intervention: Implications of the Theory of Optimum Currency Areas". Journal of International Economics, 45(2), pp. 191-209.

[5]. FIDRMUC, J. (2004): The Endogeneity of Optimum Currency Area Criteria, Intra-industry Trade, and EMU Enlargement. Contemporary Economic Policy, 2004, pp. 1-12.

[6]. FRANKEL, J., AND A. ROSE (1998): “Is EMU More Justifiable Ex Post than Ex Ante?” European Economic Review, 41, pp. 563-570.

[7]. ROSE, A. (2000): “One Money, One Market: Estimating the Effect of Common

[8]. Currencies on Trade", Economic Policy, 30, pp. 7-46.

[9]. MUNDELL, R. (1961): “A Theory of Optimum Currency Areas", American Economic Review, 51, pp. 657-665.

[10]. MUNDELL, R. (1973a): "Uncommon Arguments for Common Currencies”, In: Johnson, H. G. and Swoboda, A.K: The Economics of Common Currencies, Allen and Unwin, pp. 114-132.

[11]. HALLETT, H.A. AND PISCITELLI, L. (2001): "The Endogenous Optimal Currency Area Hypothesis: Will a Single Currency Induce Convergence in Europe?", Paper Presented at The Royal Economic Society Annual Conference, University of Durham, April 9-11.

[12]. KAWAI, M. (1987): "Optimum Currency Area", In: Eatwell, J., Milgate, M. and Newman, P. (eds.): The New Palgrave. A Dictionary of Economics, The Macmillan Press, 1987.

[13]. KRUGMAN, P. (1993): "Lessons of Massachusetts for EMU", In: Torres, G. and Giavazzi, F.: Adjustment and Growth in the European Monetary Union. Cambridge University Press, 1993, 241-261.

[14]. McKINNON, R. (1963): The Theory of Optimum Currency Area. American Economic Review, vol. 53, 1963, pp. 717-725.

[15]. MCKINNON, R. (2000): "Mundell, the Euro and Optimum Currency Areas", Journal of Policy Modeling, 22 (3), pp. 311-324.

[16]. MUNDELL, R. (1973b): “A Plan for a European Currency”, In: Johnson, H. G. and Swoboda, A.K.: The Economics of Common Currencies, Allen and Unwin, pp. 143-172. 